\title{
Determining Language Production Abilities in Indian Adolescents between 10 and 16 Years of Age: Using a Conversational based Task
}

\author{
Saniya Mariyam Rasheeka, Sudhin Karuppali, Megha Mohan \\ Department of Audiology and Speech Language Pathology, Kasturba Medical College, Mangalore, Manipal Academy of Higher Education, Manipal, \\ Karnataka, India
}

Correspondence: Sudhin Karuppali, PhD Department of Audiology and Speech-Language Pathology, Kasturba Medical College, Light House Hill Road, Mangalore 575001, India

Tel: +91-9844-807634

Fax +91-824-2428183

E-mail: sudhin.karuppali@manipal.edu

Received: April 9, 2020

Revised: August 10, 2020

Accepted: August 27, 2020
Objectives: Effective communication is an important part of social interaction significantly influenced by the mental states of communication partners. With the listener and the speaker constantly changing their thoughts and responding accordingly, a conversation is considered to be the most natural task to assess language production abilities. Therefore, the present study aimed to profile the language production abilities in Indian adolescents using a conversational based task. Methods: A total of 90 participants between 10 and 16 years of age were equally grouped into 6 groups. The research was conducted in three phases. Phase I included the development of the stimuli; Phase II included task administration; and Phase III included data and statistical analysis. The language parameters included in the study were Communication Units (CU), Statements (ST), Questions (QU), Abandoned Utterances (AU), Interrupted Utterances (IU), Response to Questions (RQ), Response to Yes/ No Questions (RYN), Response to Intonation Prompts (RIP) and Utterances with Overlapping Speech (UOS) were studied using Systematic Analysis of Language Transcripts (SALT) software. Results: The results of the study indicated a change in the usage of most of the language parameters. ANOVA test showed significant difference $(p<.05)$ for $C U, S T, Q U$, UOS, and RQ. However, a poor level of significance ( $p>$.05) was obtained for IU, AU, RYN, and RIP. Post Hoc Bonferroni test was applied to estimate the level of significance between groups. Conclusion: The research does conclude that language production abilities develop throughout adolescence, with certain linguistic parameters being potential developmental markers to assess language abilities in adolescents.

Keywords: Adolescents, Conversation, Language, Production
Language is a complex and dynamic system of conventional symbols that is used in various modes for thought and communication (American Speech-Language-Hearing Association, 1982). The ability to communicate effectively becomes an important part of social interaction which is significantly influenced by not only the mental states of both communication partners but also their cognitive skills. When considering the development of language, Hoff (2006) suggests every child differs in terms of the vocabulary and sentence structure used, and the way information is conveyed.
By preschool age, children begin to use language to tease others, and to express fantasies and jokes. While transitioning to school age, they begin to engage in longer dialogues with their narrative skills characterized with longer chains of stories, often incorporating turn taking during conversations, which becomes essential for forming bonds. Various linguistic skills have been observed to improve during adolescence (Nippold, 2016). Adolescents use appropriate interruptions, maintain and shift topics, use dramatic gestures and facial expressions to highlight crucial linguistic infor- 
mation, show empathy and make relevant remarks, contribute innovative ideas, propose amusing stories, and use appropriate narratives which becomes the essence of having an effective communication. They engage in structuring an argument that is appropriate to the listener's priorities, beliefs and values, willing to take any side of the controversy in order to arrive at a balanced solution (Nippold, Ward-Lonergan, \& Fanning, 2005).

Comprehension and production are the two domains in which language is assessed. The assessment of language comprehension does provide information about the comprehension based on the behavioral response obtained. Whereas the assessment of language production gives a direct access to the expressive form of language. The currently available language assessment methods (using norm- and criterion-referenced tests, questionnaires, interviews, developmental scales, and behavioral observations) have thus far aimed to assess the language abilities in children and adolescents. However, Damico (1993) recommends activities measuring language to be authentic, focussing on behaviours that can be observed, described, and evaluated. Further, in order to capture a true linguistic performance, Damico suggests a structured observation of actual communicative activity in real context, and functional and descriptive activities. Language sampling are often performed using naturalistic tasks which helps frame realistic interventional targets (Paul \& Norbury, 2012). In view of the importance of language production abilities in adolescent years, researchers have attempted to study and profile these abilities using narration (Staikova, Gomes, Tartter, McCabe, \& Halperin, 2013), discourse (De Marchena \& Eigsti, 2016) and visual scene based interpretation (Vaz \& Karuppali, 2019). However, there are only a handful of studies that have assessed language production abilities in adolescents using a conversational based task that takes into account the interaction between a speaker and a listener, or more communication partners, with each one having their own contributions towards the conversation either directly or indirectly (Hoey, 1983).

With the listener and the speaker constantly changing their thoughts and responding accordingly, a conversation is considered to be the most natural (Kasper \& Rose, 1999) and ultimate task to assess language production abilities. Ukrainetz and Blomquist (2002) did reveal conversational language sample anal- ysis to be more valid than the combined use of four standardized tests. According to Wells and Gordon (1985) language acquisition in children and adolescents can be adequately studied using a natural conversational context, which comprises of different types of utterances, thereby shedding light towards one's social and cognitive development. When considering other tasks, narration requires a higher level of language skills due to their inherent characteristics (which includes story grammar, organization and cohesion) (Kroenke, 2015); while picture description provides linguistic information on the syntax and semantics, it is limited to the description of only the provided picture rather than a natural scenario. Wagner, Nettelbladt, Sahlén, and Nilholm (2000) reported children with language impairment to yield more intelligible utterances and higher number of complex verb forms in a conversation than a narrative sample.

With a dire need for assessment procedures to be shifted from a structural to a more functional approach in order to examine language abilities in adolescents, it becomes vital to evaluate performances in actual context. The period of adolescence is a critical phase in life, that serves as a bridge between childhood and adulthood. An increased attention given towards this is because of the emerging realization that the present youth of India are continuously under burden, facing challenges in a community that is obsessed with the need to excel in knowledge. A successful attainment of social and linguistic goals will facilitate a healthy transition towards adulthood. Compared to the western studies which have explored language development in adolescents, there does exist a dearth of studies in the Indian context. Therefore, the present study aimed to profile the language production (using utterance types) abilities in Indian adolescents using a conversational based task.

\section{METHODS}

The present study took place in Mangaluru Taluk (an administrative division in Indian subcontinent) which is a part of the Dakshina Kannada district of the state of Karnataka, South India. Mangaluru is a multilingual city with prominent regional languages such as Tulu, Konkani, Urdu, Kannada, Malayalam, and Beary. Participants in the study included 90 typically developing 
Indian adolescents between 10 and 16 years of age, recruited from regular schools following the Central Board of Secondary Education system. Participants were classified into 6 groups across ages, with each group comprising of 15 participants (Group I included 9 males \& 6 females; Group II \& III included 8 males \& 7 females; Group IV included 7 males \& 8 females; and Group V \& VI included 11 males \& 4 females). The sample size for the current study was determined using the formula, $\mathrm{n}=Z \alpha 2 \sigma 2 / d 2$ with $95 \%$ confidence level and $90 \%$ power with reference to the study done by Appose and Karuppali (2018). An informed assent form was obtained from all the participants prior to their inclusion in the study. The participants for the current study (pilot and final data collection) were recruited based on a convenience random sampling method.

The inclusion criteria included all participants irrespective of gender to attain age adequate language skills as ascertained by the Manipal Manual of Adolescent Language Assessment (MMALA) (Karuppali \& Bhat, 2016), a norm and criterion-referenced test for assessing the language abilities in adolescents. The MMALA tests for the semantic, morphologic, and pragmatic components of language in adolescents between 10 and 16 years of age. In order to ascertain the participants English language proficiency level, the Language Experience and Proficiency Questionnaire (LEAP-Q) (Marian, Blumenfeld, \& Kaushanskaya, 2007) was used. The LEAP-Q is a validated questionnaire tool for collecting self-reported proficiency and experience data from bilingual and multilingual speakers aged between 14 and 80 years of age. As the current study did not aim to compare multilinguals, the objective of using LEAP-Q was only to ascertain the English language to be L2 for the participant, as there was a possibility for the L1 to be either any one of the six regional languages (mother tongue) as mentioned earlier. Moreover, in order to maintain uniformity in testing, English, which is commonly used in the Indian education system and which gets introduced as early as 6 years of age, was the only language assessed. The exclusion criteria included participants who had a history of speech, language, cognitive, and hearing deficits, and/or a history of transfer from more than one school, shift in the medium of instruction, or academic failures (Karuppali \& Bhat, 2014).

The study was conducted in three phases. Phase I included the development and validation of the stimuli; Phase II included the administration of the developed stimuli; and Phase III included data and statistical analysis.

\section{Phase I: Development of the stimuli}

This phase of the study involved the development of a stimuli that could elicit language production in adolescents between 10 and 16 years of age using a conversational based task. This phase was completed in 3 stages: stimuli preparation, content validation by subject experts, and pilot study.

\section{Stage 1: Stimuli preparation}

With a thorough review of the existing literature, topics for conversation were selected by considering the setting (context) and people that could be involved for the same. Thus by examining various available standardized tools, scrutinizing academic textbooks, and consulting with the grade teachers, 10 universal topics (School activities, Friends, Food, Family, Sport, School Trip, Shopping, Social media, Movies/series, and Gadgets) were considered. Further 15 probe questions were formulated under each of the shortlisted topics. Probe questions are meant to clarify and help move forward the conversation, thereby eliciting an adequate language sample required for analysis. These probe questions included 'wh' questions corresponding to the topic and therefore targeted open-ended responses.

\section{Stage 2: Content validation}

Content validation of the stimuli was performed by 3 expert Speech Language Pathologists (SLPs) having a minimum of 3 years of experience in the field of child language. The validation process of the 10 topics and the corresponding probe questions were carried out on the basis of ascertaining its appropriateness for eliciting a language production sample. Judges were required to indicate if they felt each topic to be 'appropriate', 'required modifications' or 'inappropriate'. A total of 10 probe questions were retained under each of the 10 shortlisted topics.

\section{Stage 3: Pilot study}

A pilot study was carried out on 30 participants (5 participants $\mathrm{X}$ 6 groups). The procedure for the administration of the task during 
the pilot study is mentioned in Phase II. Subsequent to the pilot study, based on the elicited responses and the unfamiliarity noted towards certain topics, a total of 5 topics (sports, school activities, social media, friends, school trip-Appendix 1) were included for the final data collection.

\section{Phase II: Task administration}

The administration of the developed stimuli on each participant took place within the school premises, in a noise-free room with the participant and the examiner sitting across from each other. The examiner was an SLP who remained constant as a conversational partner for all the participants throughout the data collection procedure in order to minimize the extent of variability in the conversation pattern. Demographic details such as date of birth, gender, standard or grade, school and schooling history were collected from each participant. Each of the 5 topics were presented to the participants on a white paper measuring $8 \mathrm{~cm}$ x 6 $\mathrm{cm}$, folded and placed in a box in order to avoid bias in the selection of a topic. After building a good rapport, the participant was instructed to randomly select any folded paper (topic) from the box and was instructed as follows, "We shall now talk about the topic (name of the topic). There is nothing right or wrong. You can tell anything that you want". If the participant was unwilling to talk about the selected topic, he/she was given an opportunity to choose another topic from the slot. The examiner used the probe questions pertaining to the corresponding topic to keep the conversation going. The language sample between the two (participant \& examiner) was recorded by a digital sound recorder (model: Sony ICD-UX560F Stereo IC recorder 4 GB) that was placed on the table amid the conversational partners. Each participant took an approximately10 to 15 minutes to complete the task.

\section{Phase III: Data and statistical analysis}

The data entry comprised of creating transcripts (of the elicited topics) (Appendix-2) of the audio-recorded conversation samples by an SLP experienced using the Systematic Analysis of Language Transcripts (SALT) software (Miller \& Iglesias, 2012). The SALT is a commonly used platform for the transcription and analysis of language output. The examiner proof-read each transcript simultaneously against the audio-recordings once the samples were completely transcribed. The transcription of a 10-minute conversation sample required an average of 1.5 hours. Though all transcripts included the language production of the participant and examiner, the focus was laid only on the participant's language production skills (which was in response to the examiner's probes). The language utterances that were studied were - Communication Units (CU), Statements (ST), Questions (QU), Abandoned Utterances (AU), Interrupted Utterances (IU), Response to Questions (RQ), Response to Yes/No Questions (RYN), Response to Intonation Prompts (RIP), and Utterances with Overlapping Speech (UOS). The frequency of occurrences of all these utterances were identified for each participant individually. Statistical analysis was performed using SPSS 25.0 version. Descriptive statistics was done to obtain the mean and standard deviation (SD) of the groups for the types of utterances - CU, ST, QU, AU, IU, RQ, RYN, RIP, and UOS. The analysis of variance test (ANOVA) was done to determine the main level of significance across the groups; while post hoc Bonferroni test was done to estimate the level of significance between groups.

\section{RESULTS}

\section{Communication Units and Statements}

The results of CU and ST does indicate Group I to have scored the least among all the groups, with a minimal increment in the mean scores observed in Group II; with Group III exhibiting a subsequent decline in mean scores. However, the mean scores of Groups IV, V, and VI showed a gradual increase. Following an increase in the mean scores, a plateau was observed at Group IV and V, with the highest frequency observed for Group VI. The results of the descriptive statistics of CU and ST are summarized in Figure 1.

The results of ANOVA test showed a statistically significant difference $(p<.05)$ for $\mathrm{CU}\left[F_{(5,84)}=12.53, p=.000\right]$ and $\mathrm{ST}\left[F_{(5,84)}=4.807\right.$, $p=.001]$ across the groups. The results of Bonferroni post hoc test for group-wise comparison of $\mathrm{CU}$ found significant differences between groups V-VI $(p<.05)$, while the other groups I-II $(p=.187)$, II-III $(p=.470)$, III-IV $(p=.077)$, and IV-V $(p=1.000)$ received a poor level of significance. However, none of the group-wise comparisons I-II ( $p=1.000)$, II-III $(p=.861)$, III-IV $(p=.720), \operatorname{IV}-\mathrm{V}(p=$ $1.000)$ and V-VI $(p=.450)$ received any significant differences for ST. 


\section{Questions}

The results of the descriptive statistics for the parameter QU indicate an increment in mean scores from Group I to II, similar to the pattern exhibited by Group V and VI. Following which a decrease in mean scores was obtained by Group III. Subsequently, Group IV achieved the highest mean scores amongst the other age groups. The results of the descriptive statistics of QU are summarized in Figure 2.

The results of ANOVA test showed a statistically significant difference $(p<.05)$ for QU $\left[F_{(5,84)}=2.709, p=.026\right]$ across the groups. The results of Bonferroni post hoc test for group-wise comparison of QU found significant differences between groups III-IV $(p<.05)$, while the other groups I-II $(p=1.000)$, II-III $(p=1.000)$, IV-V $(p=1.000)$, and V-VI $(p=1.000)$ received a poor level of significance.

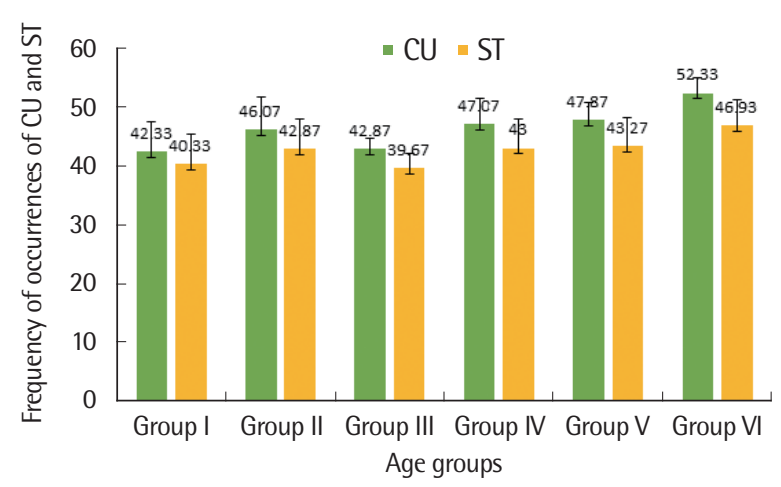

Figure 1. The mean and SD of Communication Units \& Statements across the six age groups.

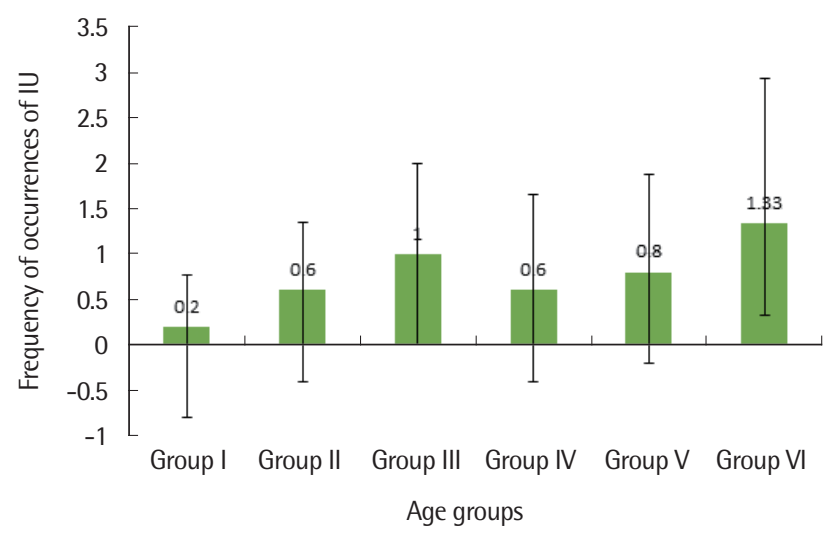

Figure 3. The mean and SD of Interrupted Utterances across the six age groups.

\section{Interrupted Utterances}

Scores for the parameter IU show a gradual increase in mean scores from Group I to III, subsequently with a drop in mean scores evidenced by Group IV. However, Group V and VI exhibited a similar pattern of growth in the mean scores. The results of the descriptive statistics of IU are summarized in Figure 3.

The results of ANOVA test showed no statistically significant difference for $\mathrm{IU}\left[F_{(5,84)}=2.032, p=.082\right]$ across the groups.

\section{Abandoned Utterances}

Results of the descriptive statistics for the parameter AU indicate a steady improvement in mean scores from Group II to VI, with group I and II attaining similar mean scores. The results of the descriptive statistics of parameter AU are summarized in Figure 4 .

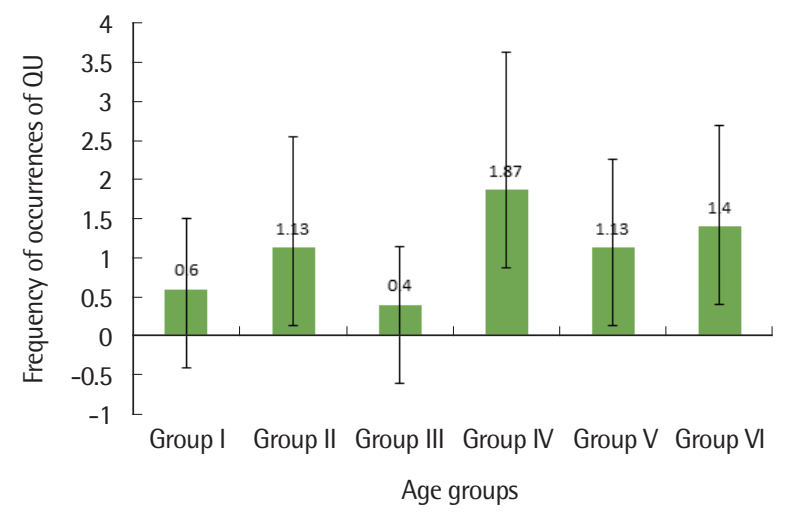

Figure 2. The mean and SD of Questions across the six age groups.

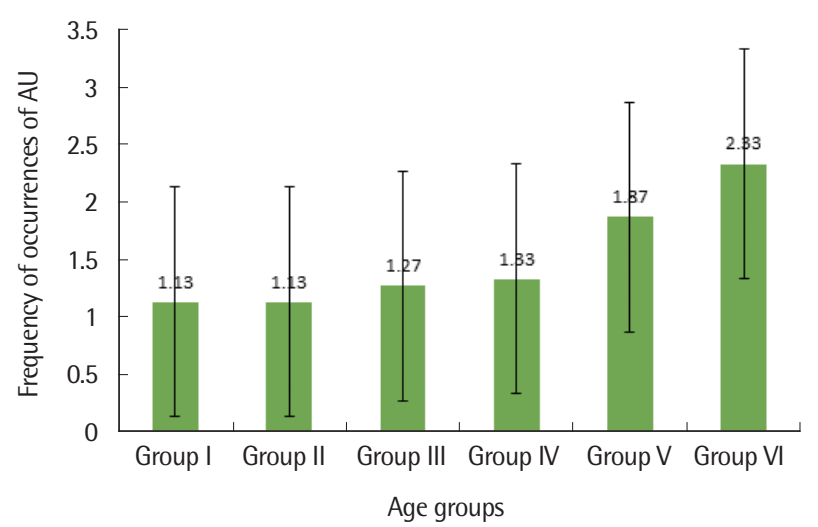

Figure 4. The mean and SD of Abandoned Utterances across the six age groups. 
The results of ANOVA test showed no statistically significant difference for $\mathrm{AU}\left[F_{(5,84)}=1.510, p=.195\right]$ across the age groups.

\section{Utterances with Overlapping Speech}

Results of the parameter UOS showed a gradual increase in mean scores from Group I to IV. A subtle decrease in mean scores were obtained by Group V, however the mean scores achieved by the subsequent Group VI formed the highest mean score achieved across the age groups. The results of the descriptive statistics of UOS are summarized in Figure 5.

The results of ANOVA test showed a statistically significant difference $(p<.05)$ for UOS $\left[F_{(5,84)}=15.721, p=.000\right]$ across the groups. The results of Bonferroni post hoc test for group-wise comparison of UOS found significant differences between groups V-VI $(p<.05)$, while the other groups I-II $(p=1.000)$, II-III $(p=1.000)$, III-IV ( $p=.116)$, and IV-V $(p=1.000)$ received a poor level of significance.

\section{Response to Questions, Response to Yes/No Questions \\ \& Response to Intonation Prompts}

The results of the descriptive statistics for the parameter RQ followed an irregular pattern of mean scores that was achieved with every alternate group obtaining mean scores lesser than the preceding and successive age groups. The lowest mean score was obtained by Group III, and the highest mean score was obtained by Group VI. The results of the parameter RYN did show an increase in mean scores from Group I to II. The subsequent groups did witness a steady decline from Group III to IV. Group V achieved the highest mean scores, however a drop in mean scores was observed

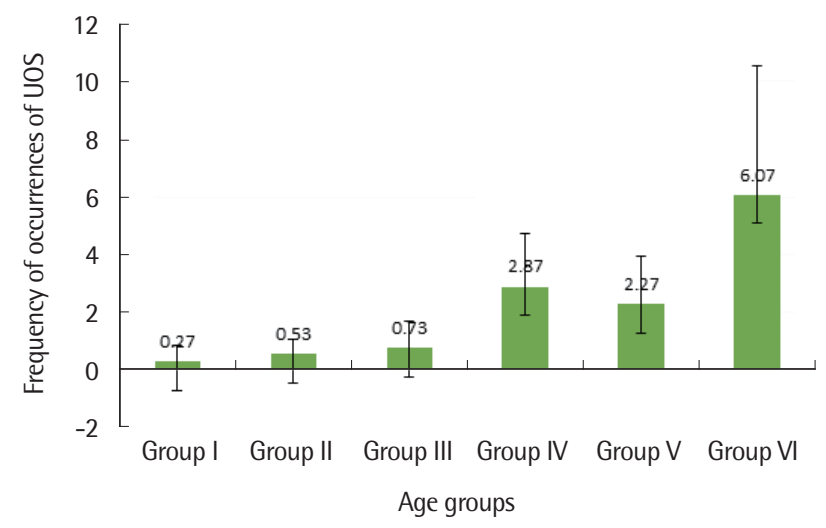

Figure 5. The mean and SD of Utterances with Overlapping Speech across the six age groups. in Group VI. The results of parameter RIP indicate the mean scores of Group I and III to be near equal, with Group II having higher mean scores than Group I and III. Group IV achieved the least mean scores, with an increase in mean scores noted for Group $\mathrm{V}$ and, a drop in mean scores in Group VI. The highest mean score achieved by Group VI was twice the lowest mean score achieved by Group IV. The results of the descriptive statistics of RQ, RYN and RIP are summarized in Figure 6.

The results of ANOVA test showed a statistically significant difference $(p<.05)$ for RQ $\left[F_{(5,84)}=2.370, p=.046\right]$ across the groups. However, there was no statistically significant difference across groups for RYN $\left[F_{(5,84)}=1.231, p=.302\right]$, and $\operatorname{RIP}\left[F_{(5,84)}=1.970\right.$, $p=.091]$. The results of Bonferroni post hoc test for group-wise comparison of RQ found poor level of significance between all the groups I-II ( $p=1.000), \operatorname{II}-\mathrm{III}(p=1.000), \operatorname{III}-\mathrm{IV}(p=.302), \operatorname{IV}-\mathrm{V}(p=$ $1.000)$, and V-VI $(p=1.000)$.

\section{DISCUSSION}

\section{Communication Units and Statements}

When considering the steady increase that was observed in the usage of CU and ST, it was evident that the exhibited linguistic units does steadily develop across age, however may not be explicitly (subsequent year-wise) observed otherwise. Older adolescents tend to orient themselves towards peers to a greater extent, thereby making use of social language as a tool to connect with each other extensively. Such interaction observed with the peer group can be attributed to the complex use of language which becomes an inte-

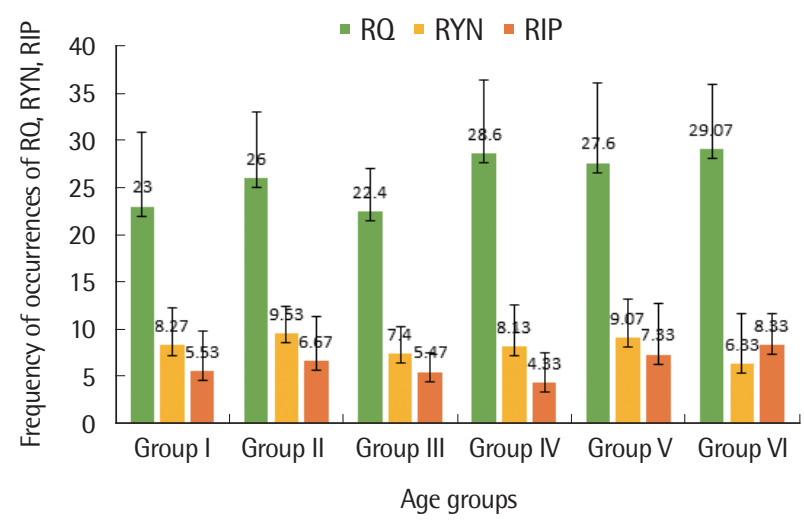

Figure 6. The mean and SD of Response to Questions, Response to Yes/No Questions, \& Response to Intonation Prompts across the six age groups. 
gral part of social interaction. A study done by Durkin and ContiRamsden (2007) reports the impact of the use of linguistic units for upholding peer group interaction, and the formation of friendships during adolescence. Positive peer relationship is noted to be advantageous in a number of ways, such as identity identification, and the development of moral judgment and values (Bishop \& Inderbitzen, 1995). Ultimately, the use of parameters such as CU and ST during conversation does help adolescents build these values which are essential during older adolescent years.

Although an overall level of significance $(p<.05)$ was obtained using ANOVA, the results of the descriptive statistics did not indicate the same. While the 10-year-olds obtained the lowest mean score, and the 15-year-olds obtained the highest scores, there were instances wherein the 13 and 14-year-olds exhibited a plateau. Moreover, the 11-year-olds performed better than the subsequent group (12-year-olds). The post hoc results of the current study indicate a significant difference only between the 14 and 15 -yearolds and not the other pairs. Such variations observed in CU and ST can be attributed to the developmental trend seen in adolescents, wherein most of the development in language is perceived to be subtle. This indicated that, certain developmental changes could be observed only when considering the age groups in clusters (Karuppali \& Bhat, 2013, 2014; Nippold, 2006; Vaz \& Karuppali, 2019). In this line, the CU and ST were also analysed using 3 cluster groups (10 and 11-year-olds; 12 and 13-year-olds; and 14 and 15-year-olds). This indicated that 10 and 11-year-old cluster group obtained the lowest mean scores with marginally higher mean scores obtained in the subsequent cluster group of 12 and 13-year-olds; while the highest mean scores were being obtained by the cluster group 14 and 15-year-olds.

\section{Questions}

The results from Figure 2 do indicate an increase in the number of QU asked by adolescents to the conversational partner. This increase in the frequency of QU can be attributed to the rising curiosity and urge to seek clarification and additional information such as the facts and knowledge of the world. However, the drop in the frequency of QU by the 12-year-olds can be attributed to the reluctance of adolescents to ask queries, due to the consequences that may arise by doing so. A question that is left unanswered may become a statement of ignorance or may give a feeling of not knowing something that one is ideally supposed to know. Adolescents may become very receptive to peer's comments, and negation, and therefore may avoid asking questions. This can be witnessed during the peak of 12 years as observed in Figure 2. However, during the later years of adolescence, asking questions becomes a mark/expression of intelligence and a desire to learn. Therefore, a shift to a positive attitude was observed in the 13,14 and 15-year-olds. Similar findings were reported by Larson and McKinley (1998) who analysed a 10 minute conversational sample between an adolescent and a peer and found an increased production of questions, interrogative reversals, wh and tag questions and use of rising intonation patterns for questioning.

An overall significance $(p<.05)$ was obtained using ANOVA while the descriptive statistics did not indicate the same. Though the 12-year-olds obtained the lowest score and the 13-year-olds obtained the highest scores, there were instances where an improvement was exhibited by 10-11 years-olds and 14-15 years-olds. The post hoc results of the current study did indicate a significant difference only between the 14 and 15-year-olds and not the other pairs. Such variations observed in QU can be attributed to the developmental trend seen in adolescents; where in most of the development in language is perceived as subtle, and therefore could be observed only when considering the age groups in clusters (Karuppali \& Bhat, 2013, 2014; Nippold, 2006; Vaz \& Karuppali, 2019). In this line, the QU was also analysed using 3 cluster groups (10 and 11-year-olds; 12 and 13-year-olds; and 14 and 15-yearolds). This indicated that the 10 and 11-year-olds obtained lowest mean scores with higher mean scores obtained in the subsequent groups of 12 and 13-year-olds; and marginally higher means scores being obtained by the 14 and 15 -year-olds.

\section{Interrupted Utterances}

When considering the results obtained for IU, it was evident that the frequency of IU followed a pattern of steady increment across the 10 and 13-year-olds. However, a drop in the frequency of IU was observed in the 14-year-olds; nevertheless, the pattern of steady improvement was again observed in the following age groups. The drop in the scores can be attributed to the transition taking place in school from higher primary school to high school, 
wherein adolescents were still in the phase of making adjustments to the roles and responsibilities that come along the academic line, as also supported by Seidman, Aber, Allen and French (1996). Adolescents are constantly reminded by teachers and parents to not interrupt in between the utterance of an adult's conversation. The underlying belief is not just the art of respecting elders but also teaching them appropriate communication skills and interpersonal boundaries. Abiding to these reminders, the IU exhibited by the 13-year-olds in the current study could have resulted in the lesser frequency of occurrences. However, the increase in IU exhibited by 11 and 12-year-olds, and the 14 and 15-year-olds may be attributed to the development of Piaget's formal operational stage across 11 and 15-years of age, which does helps in the growth of abstract thinking, and the use of logical terms, whereby their ideas may become more idealistic, and they may begin to think of endless possibilities. Therefore, when an adult expresses his/her viewpoint, the adolescent's thought process puts him in a position to interrupt the speaker's opinion and put forward his views. Larson and McKinley (1998) observed a consistent increasing trend in negative interruptions in the conversational patterns of adolescents.

Even though there was an increase in the results obtained from descriptive statistics, there was no significant difference observed using ANOVA. Therefore to further study the IU in line with cognitive development, the age groups were classified into 3 cognitive age groups (Karuppali, Babu, \& Bhat, 2017) (concrete-operational group 10-11, 11 year-olds; late-concrete and early formal-operational group 12-14, 11 year-olds; and formal-operational group $15-15,11$ year-olds). This indicated a steady increase in mean scores obtained throughout the cognitive age groups. 10-11, 11-year-old group obtained the lowest mean scores with marginally higher mean scores obtained in the subsequent cognitive group of 12-14, 11-year-olds; while the highest mean scores were being obtained by the 15-15, 11-year-olds.

\section{Abandoned Utterances}

Following the results that were obtained for the AU, a significant increase was observed in the usage of $\mathrm{AU}$ across the age groups, with a plateau observed between 10 and 11-year-olds, and 12 and 13-year-olds. This may indicate that with increase in age, adolescents may leave their utterances incomplete for the conversational partner to infer from. This is in support with the findings from a study by Karasinski and Weismer (2010) where they found adolescents to infer during discourse processing, thereby abandoning utterances midway. Adolescents are also aware that the listener will be able to successfully construct a coherent message from incomplete utterances of a speaker. This thought process of the adolescent about his/her communication partner can be associated to their higher order executive functions, wherein thinking abstractly and reflecting (cognitive competence) upon themselves develop with age. Such executive functions are reported to steadily develop throughout adolescence.

It was noticed in the current study that a greater number of older adolescents tended to leave utterances incomplete when compared to the younger adolescents. However even though there was an increase in the results obtained from descriptive statistics, there was no significant difference observed using ANOVA. Therefore to further study the $\mathrm{AU}$ from a cognitive perspective, the age groups were classified into 3 cognitive age groups (concrete-operational group 10-11, 11-year-olds; late-concrete and early formaloperational group 12-14, 11-year-olds; and formal-operational group 15-15, 11-year-olds) as used by the study done by Karuppali et al. (2017). This indicated a steady increase in the mean scores obtained throughout the cognitive age groups. The 10-11, 11-yearolds obtained the lowest mean scores with marginally higher mean scores obtained in the subsequent cognitive group of 12-14, 11-year-olds; while the highest mean scores were obtained by the 15-15, 11-year-olds.

\section{Utterances with Overlapping Speech}

From the results obtained, it can be observed that the frequency of UOS during a conversation was evident in the form of adolescent's utterances, coinciding with the speaker's final utterances/ segment of a communication unit, which was observed to be increasing with age. This increase in the occurrence of UOS can be attributed to the nature of adolescent's feeling/thought/ideology that voicing out opinions becomes an integral part of a conversation. In order to sound as an equally contributing conversation partner, adolescents mimic adult's way of communicating by initiating a linguistic unit even before the preceding speaker's utterance 
is complete. The result of the current study does observe older adolescents to overlap his/her speech a greater number of times when the speaker had raised a question. Conversely, younger adolescents tended to patiently listen until the speaker's communication unit was complete, thereby resulting in fewer occurrences of UOS.

An overall significance $(p<.05)$ was obtained using ANOVA indicating that there was an overall change in the occurrence of UOS. The post hoc results of the current research indicate a significant difference only between the 14 and 15-year-olds, and not the other pairs. Such variations observed in UOS can be attributed to the developmental trend seen in adolescents, where in most of the development in language are perceived to be subtle. This indicated that, certain developmental changes could be observed only when considering the age groups in clusters (Karuppali \& Bhat, 2013, 2014; Nippold, 2006; Vaz \& Karuppali, 2019). In this line, the UOS were also analysed using 3 cluster groups (10 and 11-year-olds; 12 and 13-year-olds; and 14 and 15-year-olds). This indicated that 10 and 11-year-olds obtained the lowest mean scores with higher mean scores obtained in the subsequent groups of 12 and 13-year-olds; the highest mean scores were obtained by the 14 and 15 -year-olds.

\section{Response to Questions, Response to Yes/No Questions, Response to Intonation Prompts}

As indicated in the Figure 6 the parameters RQ and RIP did increase with age, while RYN decreased with age even though a clear pattern of rise and fall of mean scores was not observed. While it is a conversation, there are questions exchanged back and forth in order to mark the presence of both the conversational partners' attention and understanding. Therefore, answering to the questions posed becomes essential for the speaker in order to receive a feedback of the delivery of the message. Though the response to questions may either include a verbal or a non-verbal gesture of nodding, using facial expressions, or any other mode, the present study focused only on the verbal responses. With increase in age, due to the development of other aspects of language such as semantics and syntax, the 13 to 15 -year-olds were in a better position to respond to the questions posed. Similarly, when intonation prompts were given, it does demand the conversation partner of the listener to urge the speaker to go ahead with his/her part of the conversation. However, intonation prompts can be used for a vari- ety of reasons just by changing the intonation patterns. In the present study, intonation prompts were used to elicit further response from the adolescent. It was observed that the response rate increased when intonation prompts were delivered. Unlike RQ and RIP, RYN showed reduced responses with increase in age. This could be attributed to the ability to infer in adolescents, making them assume that it is inherently understood to the listener if his/her response is a 'yes' or 'no' from the previous statements. It can also be attributed to the sequence of questions asked, where if the conversation partner has asked a 'yes' or 'no' to confirm a statement or opinion previously discussed or if the question was posed to ask something new. The latter type of questions received more responses than the former type. This again does support the earlier statement regarding the development of the ability to think and make an inference.

Amongst all 3 parameters, only RQ had a significance $(p<.05)$ across age groups from the results of ANOVA test. The variations observed in RQ, RYN, and RIP can be attributed to the developmental trend seen in adolescents, wherein most of the development in language is perceived to be subtle. Although cluster and cognitive wise grouping was done, there was no significant difference obtained. This could be attributed to the nature of the parameter being very subtle, and that parameters such as RQ, RYN, and RIP may not be ideal developmental markers when it comes to assessing adolescent language.

Overall, it has been evidenced that certain parameters such as CU, ST, QU, AU, IU, and UOS showed developmental changes across the ages when compared to parameters like RQ, RYN, and RIP. Using a conversational based task in adolescents has yielded a pattern of changes in the language structure. The changes in these language parameters may be attributed to increased exposure to literacy rich environment (Reed, 2005), changes in personality, growth in cognitive abilities, increased experiences of the world (Locke \& Bogin, 2006), interaction with different communication partners (Eckert, 2003), watching language rich movies/series, and socialization skills.

\section{CONCLUSION}

It has been evidenced that language development continues 
throughout adolescence and utterances such as CU, ST, QU, AU, IU, and UOS can be considered as developmental markers for the evaluation of language sample in adolescents. These developmental markers may help frame effective interventional targets. The findings of the current study conclude conversation to be considered as a potential supplement to the currently available tasks and tools for the assessment of an adolescent with language disability. This study did not have sufficient control over the characteristics of the conversational partner in terms of their received training, however the authors did use probe questions as interaction guidelines. With the current study having adopted a relatively smaller sample size, future studies are recommended to consider this issue, along with controlling for the characteristics of the conversational partner, gender and tester bias which was not within the scope of the present study. With very few similar studies done in Asian countries, there is good scope for exploring the same on similar grounds, thereby opening up new avenues of research on cultural differences on language production abilities.

\section{REFERENCES}

American Speech-Language-Hearing Association. (1982). Language. American Speech-Language Hearing Association.

Appose, A., \& Karuppali, S. (2018). Decoding the macrostructural form of oral narratives in typically developing children between 6-11 years of age: using story grammar analysis. Online Journal of Health and Allied Sciences, $17(1), 1-8$.

Bishop, J. A., \& Inderbitzen, H. M. (1995). Peer acceptance and friendship: an investigation of their relation to self-esteem. The Journal of Early Adolescence, 15(4), 476-489.

Damico, J. S. (1993). Language assessment in adolescents: addressing critical issues. Language, Speech, and Hearing Services in Schools, 24(1), 29-35.

De Marchena, A., \& Eigsti, I. M. (2016). The art of common ground: emergence of a complex pragmatic language skill in adolescents with autism spectrum disorders. Journal of Child Language, 43(1), 43-80.

Durkin, K., \& Conti-Ramsden, G. (2007). Language, social behavior, and the quality of friendships in adolescents with and without a history of specific language impairment. Child Development, 78(5), 1441-1457.

Eckert, P. (2003). Language and adolescent peer groups. Journal of Language and Social Psychology, 22(1), 112-118.
Hoey, M. (1983). On the surface of discourse. London: Allen \& Unwin.

Hoff, E. (2006). How social contexts support and shape language development. Developmental Review, 26(1), 55-88.

Karasinski, C., \& Weismer, S. E. (2010). Comprehension of inferences in discourse processing by adolescents with and without language impairment. Journal of Speech, Language, and Hearing Research, 53(5), 1268-1279.

Karuppali, S., Babu, S., \& Bhat, J. S. (2017). Lexical density and diversity in written language of adolescents between 10-16 years of age. Journal of the Indian Academy of Applied Psychology, 43(2), 316-325.

Karuppali, S., \& Bhat, J. S. (2013). Understanding of idiomatic expressions in children between 11-14 years. International Journal of English and Education, 2(1), 1-10.

Karuppali, S., \& Bhat, J. S. (2014). Efficacy of using simile completion tasks as a measure to evaluate the figurative language abilities in adolescents aged between 10-15 years. Nepal Journal of Medical Sciences, 3(2), 110-115.

Karuppali, S., \& Bhat, J. S. (2016). Manipal Manual of Adolescent Language Assessment. Manipal, India: Manipal University Press.

Kasper, G., \& Rose, K. R. (1999). Pragmatics and SLA. Annual Review of Applied Linguistics, 19, 81-104.

Kroenke, C. (2015). Comparison of conversation and narrative language abilities in children with autism: diagnostic and therapeutic considerations (Master's thesis). University of Wisconsin, Milwaukee, U.S.A.

Larson, V. L., \& McKinley, N. L. (1998). Characteristics of adolescents' conversations: a longitudinal study. Clinical Linguistics \& Phonetics, 12(3), 183-203.

Locke, J. L., \& Bogin, B. (2006). Language and life history: a new perspective on the evolution and development of linguistic communication. Behavioral and Brain Science, 29, 259-325.

Marian, V., Blumenfeld, H. K., \& Kaushanskaya, M. (2007). The Language Experience and Proficiency Questionnaire (LEAP-Q): assessing language profiles in bilinguals and multilinguals. Journal of Speech Language and Hearing Research, 50(4), 940-967.

Miller, H., \& Iglesias. (2012). SALT: systematic analysis of language transcripts [Research version]. Middleton, WI: SALT Software.

Nippold, M. A. (2006). Language development in school-age children, adolescents, and adults. In K. Brown (Ed.), Encyclopedia of language and linguistics (2nd ed.) (pp. 368-372). Oxford, UK: Elsevier Publishing.

Nippold, M. A. (2016). Later language development: school-age children, adolescents, and young adults. Austin, TX: Pro-Ed.

Nippold, M. A., Ward-Lonergan, J. M., \& Fanning, J. L. (2005). Persuasive 
writing in children, adolescents, and adults. Language Speech and Hearing Services in Schools, 36(2), 125-138.

Paul, R., \& Norbury, C. (2012). Language disorders from infancy through adolescence-E-Book: listening, speaking, reading, writing, and communicating (4th ed.). St. Louis, MO: Mosby.

Reed, V. (2005). An introduction to children with language disorders (3rd ed.). Boston: Allyn and Bacon.

Seidman, E., Aber, J. L., Allen, L., \& French, S. E. (1996). The impact of the transition to high school on the self-system and perceived social context of poor urban youth. American Journal of Community Psychology, 24(4), 489-515.

Staikova, E., Gomes, H., Tartter, V., McCabe, A., \& Halperin, J. M. (2013). Pragmatic deficits and social impairment in children with ADHD. Journal of Child Psychology and Psychiatry, 54(12), 1275-1283.
Ukrainetz, T. A., \& Blomquist, C. (2002). The criterion validity of four vocabulary tests compared with a language sample. Child Language Teaching and Therapy, 18(1), 59-78.

Vaz, L., \& Karuppali, S. (2019). Estimating the pragmatic language abilities in Indian adolescents between 10 and 16 years of age: using contextually flooded visual scenes. Communication Sciences \& Disorders, 24(3), 656672.

Wagner, C. R., Nettelbladt, U., Sahlén, B., \& Nilholm, C. (2000). Conversation versus narration in pre-school children with language impairment. International Journal of Language \& Communication Disorders, 35(1), 8393.

Wells, G., \& Gordon, W. (1985). Language development in the pre-school years (Vol. 2). Cambridge: Cambridge University Press. 
Appendix 1. Topics and probe questions

\begin{tabular}{|c|c|}
\hline Topics & Probe questions \\
\hline \multirow[t]{13}{*}{ Sports } & 1. Which is your favourite game? \\
\hline & a. If Cricket; why do you prefer cricket over football? How is the game played? \\
\hline & b. If football; why do you prefer football over cricket? How is the game played? \\
\hline & c. If any other indoor game; why do you prefer an indoor game over an outdoor game? \\
\hline & 2. How do you work as a team in Cricket/Football? \\
\hline & 3. What are the qualities you should have to be a good sport person? \\
\hline & 4. What have you gone through to achieve a trophy or medal? \\
\hline & 5. What was your experience during last year's sports day? Or What are the sports you took part in last year's sports day? \\
\hline & 6. Describe one best moment that you can never forget? \\
\hline & 7. What are the sports you play in your society/neighbourhood? \\
\hline & 8. Are you into any sports organisation? Are you a member in any sports organisation? If yes, how does a sport organisation function? \\
\hline & 9. How does a coach/Physical Education Teacher help you in forming a better sports person? \\
\hline & 10. Why does playing an outdoor game help build physical health? \\
\hline \multirow[t]{10}{*}{ School activities } & 1. Name some activities that take place in school. \\
\hline & 2. What are the activities that you take part in? \\
\hline & 3. How do these activities take place? Tell me more... \\
\hline & 4. Why do you think these activities are held at school? \\
\hline & 5. How have these activities benefitted you or your classmates? \\
\hline & 6. How does your teacher guide you through the activity? \\
\hline & 7. How does having a team help during school activities? \\
\hline & 8. When do these activities take place? \\
\hline & 9. How do you all practice for the upcoming activity like school/annual day? \\
\hline & 10. In my opinion, school activities improve your skills. What do you say? \\
\hline \multirow[t]{10}{*}{ Social media } & 1. Social media good or bad? \\
\hline & 2. Facebook or Instagram? \\
\hline & 3. Preference for audio or video calls? \\
\hline & 4. Do you think you have enough time to spend on social media? \\
\hline & 5. What is your parent's opinion about you using social media for extended period? \\
\hline & 6. Influence of social media on studies? \\
\hline & 7. Who is your favourite Youtuber? \\
\hline & 8. Does social media help you connect to people? \\
\hline & 9. Social media made life easier? \\
\hline & 10. Do you use Tiktok or any other video making apps? \\
\hline \multirow[t]{10}{*}{ Friends } & 1. What kind of friends do you have? Like; for e.g., food friend, school friend, neighbourhood friend? \\
\hline & 2. How well do you know your friend/s? \\
\hline & 3. What do you all do when you have free time? \\
\hline & 4. What do you all plan on? Something exciting? \\
\hline & 5. Do your friends fight with you? If yes, why? \\
\hline & 6. How do you solve when your friend fights with you? \\
\hline & 7. Do you all do your homework/assignments together? \\
\hline & 8. Does your friend help you when you are in need? or Why does your friend help you? \\
\hline & 9. Why is it important to have friends at school? \\
\hline & 10. How do you identify if one is a good friend or not? \\
\hline
\end{tabular}


Appendix 1. Continued

\begin{tabular}{ll}
\hline Topics & \multicolumn{1}{c}{ Probe questions } \\
\hline School trip or excursion & 1. How do you plan a trip with friends? \\
2. A memorable trip \\
3. What do you set a bag for a 3-day trip? \\
4. Which is the place that you want to visit? \\
5. Last trip you had with your family. Share the details. \\
6. When is the first time you travelled by train? How was your experience? \\
7. What mode of transport would you choose and why? \\
8. What are the places you've visited so far? \\
9. Would you choose to travel with friends or with family? \\
10. Where did you go last year as a part of school trip?
\end{tabular}




\section{Appendix 2.}

A sample of a SALT transcript using conventions of the parameters of interest

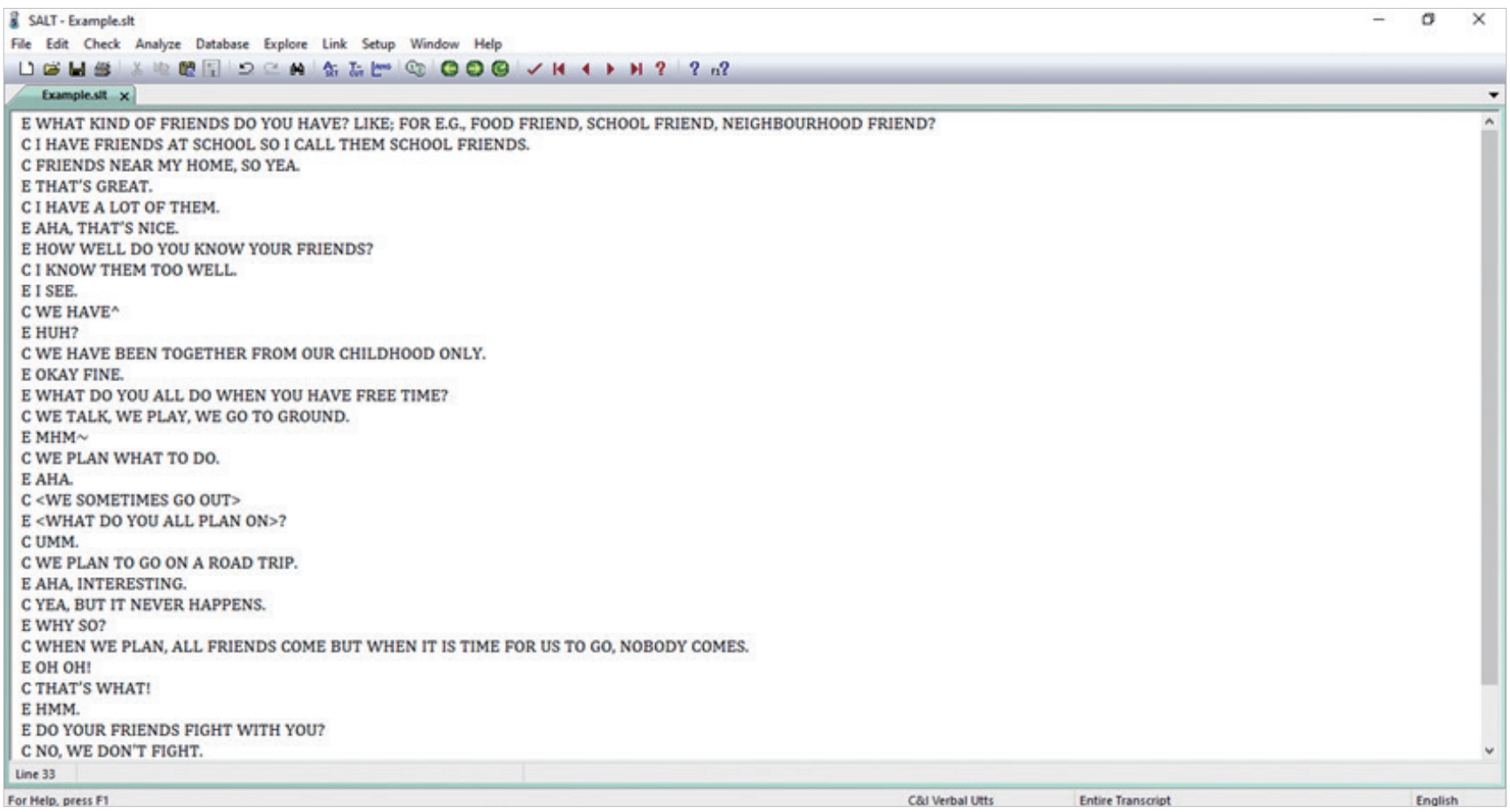

A sample of a SALT result which was used in the present study

\begin{tabular}{|c|c|c|c|c|}
\hline \multicolumn{5}{|c|}{$\begin{array}{l}\text { SALT-Example_TS } \\
\text { File Edit Check Analyze Database Explore }\end{array}$} \\
\hline \multicolumn{5}{|c|}{ 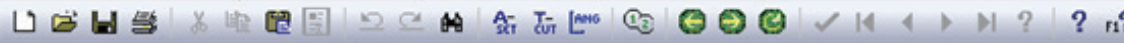 } \\
\hline \multicolumn{5}{|c|}{ Example.sit Example_TS $\times$} \\
\hline \multicolumn{5}{|l|}{ Example } \\
\hline \multicolumn{5}{|c|}{ TRANSCRIPT SUMMARY } \\
\hline & \multicolumn{2}{|c|}{ Child } & \multicolumn{2}{|c|}{ Examiner } \\
\hline & number & percent & number & percent \\
\hline TOTAL UTTERANCES & 50 & & 92 & \\
\hline Statements (.) & 43 & 86.00 & 20 & 21.74 \\
\hline Exclamations (!) & 0 & $\cdots$ & 0 & -. \\
\hline Questions (?) & 0 & $\ldots$ & 63 & 68.48 \\
\hline Intonation Prompts $(\sim)$ & 1 & 2.00 & 7 & 7.61 \\
\hline Abandoned Utterances $(\gg)$ & 5 & 10.00 & 1 & 1.09 \\
\hline Interrupted Utterances $\left({ }^{\wedge}\right)$ & 1 & 2.00 & 1 & 1.09 \\
\hline Verbal Utterances & 50 & 100.00 & 92 & 100.00 \\
\hline Nonverbal Utterances & 0 & - & 0 & - \\
\hline Unintelligible Utterances & 2 & 4.00 & 0 & - \\
\hline Partly Intelligible Utterances & 0 & -. & 0 & - \\
\hline Responses to Questions & 39 & 78.00 & 0 & - \\
\hline Yes/No Responses to Questions & 8 & 16.00 & 0 & $\cdots$ \\
\hline Responses to Intonation Prompts & 7 & 14.00 & 1 & 1.09 \\
\hline Imitations & 0 & - & 2 & 2.17 \\
\hline One-word Utterances & 22 & 44.00 & 25 & 27.17 \\
\hline Utterances with Mazes & 0 & $\cdots$ & 0 & - \\
\hline Utterances with Pauses & 0 & - & 0 & - \\
\hline Utterances with Omissions & 0 & - & 0 & $\cdots$ \\
\hline Utterances with Overlapping Speech & 2 & 4.00 & 2 & 2.17 \\
\hline Utterances with Word Codes & 0 & $\ldots$ & 0 & -.. \\
\hline Utterances with Utterance Codes & 0 & $\ldots$ & 0 & - \\
\hline
\end{tabular}




\section{국문초록}

Determining Language Production Abilities in Indian Adolescents between 10 and 16 Years of Age: Using a Conversational based Task

Rasheeka Saniya Mariyam · Sudhin Karuppali · Megha Mohan

Kasturba Medical College, Manipal Academy of Higher Education

배경 및 목적: 의사소통은 대화 상대자의 지적 상태에 영향을 받는 사회적 상호작용이다. 다양한 발화로 이루어진 대화가 언어산출 능 력을 평가할 수 있는 가장 자연스러운 자료를 제공할 수 있다. 이에 본 연구는 대화에 기반한 과제를 사용하여 인도 청소년의 발화 발달 특성을 측정하고자 하였다. 방법: 10-16세의 총 90 명의 참가자가 여섯 연령대로 분류되었다. 본 연구는 자극개발 1단계, 실시 2단계, 분 석 3단계 등 총 3 단계로 구성되었다. 본 연구에서는 의사소통 유닛(CU), 진술(ST), 질문(QU), 포기된 발화(AU), 방해받은 발화(IU), 질 문 대답(RQ), 예/아니오 응답(RYN), 억양에 대한 응답(RIP), 중첩된 발화(UOS) 등을 SALT 프로그램을 이용하여 분석하였다. 결과: 대부분의 발화유형에서 변화가 관찰되었다. 아노바 결과, $\mathrm{CU}, \mathrm{ST}, \mathrm{QU}, \mathrm{UOS}, \mathrm{RQ}$ 에서 유의한 차이가 관찰되었다( $p<.05)$. 하지만 IU, $\mathrm{AU}, \mathrm{RYN}, \mathrm{RIP}$ 에서는 유의한 차이가 관찰되지 않았다( $p>.05)$. 집단 간 차이를 살펴보기 위하여 본페로니 사후검증을 실시하였다. 논 의 및 결론: 본 연구 결과는 청소년기에도 언어산출능력이 발전한다는 점을 시사한다. 특히 일부 발화유형은 청소년의 언어능력을 측 정하는데 유용할 것이다.

핵심어: 청소년, 대화, 언어, 산출

\section{참고문헌}

Vaz, L., \& Karuppali, S. (2019). 문맥 그림 자극을 사용한 10-16세 인도 청소년의 화용 언어능력 평가. Communication Sciences \& Disorders, 24(3), 656-672.

\section{ORCID}

Rasheeka Saniya Mariyam (제1저자, 대학원생 https://orcid.org/0000-0002-1800-3854);

Sudhin Karuppali (교신저자, 부교수 https://orcid.org/0000-0003-2955-8107);

Megha Mohan (공동저자, 조교수 https://orcid.org/0000-0001-5940-0293) 